\title{
Sosyal Görünüş Kaygısında Cinsiyet Farklılıkları: Bir Meta Analiz Çalışması
}

\author{
DOI: 10.26466/opus.519967 \\ * \\ Zeynep Şimşiri*- Tolga Seki** $-\underline{\text { Bülent Dilmaç }}$ \\ * Arş. Gör., Necmettin Erbakan Üniversitesi, Ereğli Eğitim Fakültesi, Ereğli / Konya / Türkiye \\ E-Posta: zey.simsir.93@gmail.com \\ ORCID: 0000-0003-2353-8922 \\ ** Arş. Gör., Necmettin Erbakan Üniv., Ahmet Keleşoğlu Eğitim Fak., Meram / Konya/ Türkiye \\ E-Posta: $\underline{\text { tg.seki@gmail.com }}$ \\ ORCID: $0000-0001-5594-0786$ \\ *** Prof. Dr., Necmettin Erbakan Üniv., Ahmet Keleşoğlu Eğitim Fak., Meram / Konya/ Türkiye \\ E-Posta: bulentdilmac@gmail.com \\ ORCID: $\underline{0000-0001-5753-9355}$
}

\section{Öz}

Bu araştırmanın amacl, sosyal görünüş kaygısı düzeyinin cinsiyetler açısından farklılık gösterip göstermediğini ortaya koymaya yönelik bir meta-analiz çalışması yapmaktır. Bu araştırmada etki büyüklüğ̈̈ katsayısı olarak Cohen d kullanılmıştır. Araştırma kapsamında yapılan alan yazın taramasında konu ile ilgili Türkiye'de 2013-2018 yılları arasında yürütülen 129 çalışma belirlenmiştir. Dâhil edilme ölçütleri doğrultusunda 10'u tez, 14'ü makale, 5'i tezden üretilmiş makaleden oluşan 29 çalışma araştırmaya dâhil edilmiştir. Araştırmanın çalışma grubu 7340'si kadın ve 6425'si erkek, toplam 13765 kişiden oluşmaktadır. Dâhil edilen çalışmalarda heterojen bir dağgllım belirlenmiştir $(Q=100,628 ; p<.01$; 72,175). Araştırma sonucunda, rastgele etkiler modeline göre sosyal görünüş kaygısı erkeklerde kadınlardan daha yüksek çıkmıştır ancak; elde edilen değer önemsiz düzeydedir (Cohen d=0,040). Yapılan moderatör analizi ile sosyal görünüş kaygısı, cinsiyet açısından örneklem grubuna (ergen/yetişkin) göre incelenmiş, analiz sonucu ergen ve yetişkinlerin örneklem grubuna göre cinsiyete göre etki büyüklü̈̆̈̈ değerinin istatistiksel olarak anlaml farklllı göstermediği görülmüştür ( $Q b=0,382, p>0,05)$. Araştırma sonuçları literatür ışığında tartışılmış ve önerilerde bulunulmuştur.

Anahtar Kelimeler: Sosyal görünüş kaygısı, Vücut imgesi, Meta-analiz, Cinsiyet 


\title{
Gender Differences in Social Appearance Anxiety: A Meta-Analysis Study
}

\begin{abstract}
The aim of the curent study is to conduct a meta-analysis to whether the social appearance anxiety level is different in terms of gender. In this study, Cohen d was used as the effect size coefficient. 129 studies conducted on the subject in the years 2013 to 2018 were identified in Turkey during the literature review process. 29 studies (10 theses, 14 articles and 5 theses articles) which were appropriate for inclusion criteria were concluded. The total sample of study was 13765 people, 6425 of whom were males and 7365 whom were females. According to the homogeneity test, heterogeneous distribution was identified in the studies included $(Q=100,628 ; p<.01 ; 72,175)$. As a result of the research, social appearance anxiety was higher in males than females, but this value is negligible (Cohen $d=0,040$ ). Social appearance anxiety was examined according to the sample group (adolescent / adult) by the moderator analysis, and the effect size value by gender was not statistically significant according to the sample group. ( $Q b=0,382$, $p>0,05)$. The conclusion of the study was discussed and suggestions are given in line with the literature.
\end{abstract}

Keywords: Social appearance anxiety, Body image, Meta-analysis, Gender 


\section{Giriş}

Toplumsal bağlamda yaşamını sürdüren insan, etkileşimde bulunduğu diğer insanlara karşı birtakım değerlendirmelerde bulunmaktadır. Bu değerlendirmeler ilk etapta fiziksel görünüşle ilgili olup, bireylerin birbirleri ile kuracağı iletişim stilini, kendini diğerlerine yakın veya uzak hissetmesini doğrudan etkilemektedir (Kılıç, 2015). Literatürde, güzel görünüşlü insanların kişilerarası, sosyal ve iş yaşamında daha avantajlı bir yere sahip olduğu sıklıkla vurgulanmıştır (Heilman ve Stopeck, 1985). İnsanların çoğu diğerleri üzerinde bıraktıkları izlenimin ne kadar önemli olduğunun farkındadır. Dolayısı ile diğerleri üzerinde iyi bir izlenim uyandırmak için çaba gösterirler. İnsanların diğerlerinin kendisi hakkında ne düşündüğü konusunda endişelenmesi veya kafa yorması uygun bir davranış olmasa da doğal ve anlaşılabilir bir durumdur (Leary ve Kowalski, 1995).

İnsanlar, kendi fiziksel özelliklerinin farkında olup bunun üzerinde bir algıya sahiptir (Çınar ve Keskin, 2015; Gofmann, 1959; Leary ve Kowalski, 1990). Bu algının şekillenmesinde kültürel ve toplumsal ögeler, demografik özellikler, medya, kitle iletişim araçları ve moda önemli bir etkiye sahiptir. Bu unsurlar, ideal olarak kabul edilen vücut yapısı ve bu ideal yapının etkisinde kalan bir ideal görünüş imgesi geliştirir (Çepikkurt ve Coşkun, 2010; Grogan, 2008; Kılıç, 2015; Smolak, 2002). Kişinin sahip olduğu benlik algısının, dayatılan bu ideal vücut imgesi ile uyuşmaması, kişinin kendisini kabul etmemesine ve kendi görünüşü hakkında olumsuz bir görünüş algısı geliştirmesine yol açar (Kılıç, 2015; Sabiston, Crocker, ve Munroe-Chandler, 2005).

Bireyin fiziksel görünüşüne ilişkin alg1sı psikoloji literatüründe beden alg1s1 "body image" olarak isimlendirilmektedir (Banfield ve McCabe, 2002; Cash, 2004; Grogan, 2008). Grogan (2008), vücut imgesini kişinin vücuduna dair duygu, düşünce ve algıları şeklinde ifade etmiştir. Kişinin kendi bedeniyle etkileşimde bulunması olarak değerlendirilebilecek olan bu algı olumlu ya da olumsuz olabilmektedir (Doğan, Sapmaz, ve Totan, 2011). Olumlu beden imajina sahip bireyler vücutlarının genel görünüşüne karşı pozitif bir tutuma sahiptir ve bedenlerinden memnuniyetlerini ifade ederler. Olumsuz beden imajına sahip bireyler ise, vücutlarının genel görünüşüne karşı negatif bir tutuma sahiptir ve vücutlarıyla 
ya da herhangi bir organları ile ilgili olumsuz düşünce ve duygulara sahiptir. Bu kişiler kendilerini diğer insanlara göre çok daha az çekici bulduğunu, bedeniyle ilgili kendisini rahatsız hissettiğini ve bedeninden utandığını ifade ederler (Doğan, 2010; Grogan, 2008).

Bireyin bedeniyle ve fiziksel görünüşüyle ilgili olumsuz beden imajına sahip olması sosyal görünüş kaygısı olarak adlandırılmaktadır (Doğan, 2010). Sosyal görünüş kaygisı, sosyal kaygının bir alt boyutudur ve bireyin fiziksel görünüşüne ilişkin diğer insanların değerlendirmelerini içeren endişeler olarak tanımlanmıştır (Hart, Leary, ve Rejeski, 1989; Hart, Flora, Palyo, Fresco, Holle, ve Heimberg, 2008). Hart ve arkadaşları (2008), sosyal görünüş kaygısını, sadece boy, kilo gibi fiziksel özellikleri içermekten ziyade, bireyin ten rengi, göz rengi, yüz yapısı gibi bileşenlerinin de sosyal görünüş kaygısı kapsamında olduğunu ifade etmiştir. Vücut şeklinin başkaları tarafından nasıl değerlendirildiği ile ilgilenmeyen kişiler düşük düzeyde sosyal görünüş kaygısı deneyimlerken; fiziksel görünüşlerine ilişkin olumsuz mantıkdışı düşüncelere sahip olanlar ve diğerlerinin kendi görünüşü hakkında olumsuz değerlendirmelerine duyarlı olan kişiler kronik olarak sosyal görünüş kaygısı yaşamaktadır (Hart, Leary, ve Rejeski, 1989). Özetle sosyal anksiyete bozukluğu ve sosyal görünüş kaygısının temelinde başkaları tarafından olumsuz değerlendirilme korkusu yer almaktadır (Doğan, 2009).

Çağımızda kadın ve erkeklere dayatılan beden imajının başta ergenler olmak üzere küresel bağlamda çok sayıda insan üzerinde sosyal görünüş kaygısı yarattı̆̆ı araştırmacıların dikkatini çekmiş ve konu üzerinde ulusal ve uluslararası boyutta çok sayıda araştırma yapılmıştır. Yapılan araştırmalarda sosyal görünüş kaygısı ile ilişkili olan başlıca unsurlar; benlik saygısı (A ğırnasligil ve Amuk, 2017; Kılıç, Karakuş, 2016; Özcan, Subaşı, Budak, Çelik, Gürel, ve Yıldız, 2013; Işıkol Özge, 2013; Türker, Er, Eroğlu, Şentürk, ve Durmaz, 2018), mükemmeliyetçilik (Levinson ve ark., 2013), negatif değerlendirilme korkusu (Karaca Doğan, 2018; Levinson ve ark., 2013; Levinson, ve Rodebaugh, 2012), öz-yeterlilik (Sahin, Barut, Ersanli, ve Kumcagiz, 2014; Vural, Keskin, ve Çoruh, 2017), yalnızlık (Amil ve Bozgeyikli, 2015), öznel iyi oluş ve değer (Seki ve Dilmaç, 2015), beden dismorfik semptomlar (Mastro, Zimmer-Gembeck, Webb, Farrell, ve Waters, 2016), fiziksel aktiviteye katılım (Alemdağ ve Öncü, 2015; Erman, 2017), algılanan sosyal destek (Atik, Atik, Asaf, ve Cinar, 2015), sosyal 
medya kullanım düzeyi (Çakmak, 2018), mutluluk (İsmail, 2018), yoğun ve bağımlı internet kullanımı (Korkmaz, 2017) şeklinde sıralanabilir.

Türkiye'de yapılan çalışmalara bakıldığında sosyal görünüş kaygısını demografik değişkenler açısından inceleyen çok sayıda çalışma vardır. Araştırma kapsamında incelediğimiz, sosyal görünüş kaygısının cinsiyete göre farklılaşıp farklılaşmadığını inceleyen araştırmalarda farklı sonuçlar elde edilmiştir. Türkiye'de yapılan çalışmaların bir kısmında cinsiyete göre anlamlı farklılaşma görülmezken (Altun Dinc, 2016; Ben, 2017; Ersanli, 2013; Göksel, Caz, Yazıcı, ve Zorba, 2018; Gül, 2016; Kalemoglu Varol, Erbas, Unlu, 2014; Sahin, Barut, ve Tekeli, 2017) bir kısminda erkeklerin (Alemdağ ve Öncü, 2015; Ciba, 2018; Çelik, Turan, 2014; Senger, 2017; Soylu, Atik, ve Ocalan, 2017; Var, Karabulut, ve Atasoy, 2018) ya da kadınların (Atik, Atik, Asaf, ve Cinar, 2015; Dönmez, 2018; Erdemir, Bagci, İnan, ve Turan, 2013) lehine anlamlı sonuçlara ulaşılmıştır.

Yukarıdaki açıklamalar ve alan yazında yapılan çalışmalar göz önüne alındığında sosyal görünüş kaygısının cinsiyete göre farklılaşıp farklılaşmadığının incelenmesinin ihtiyaç olduğu kanaati doğmuştur. Ulusal ve uluslararası literatür tarandığında bu konuda herhangi bir meta analiz çalışmasına rastlanmamıştır. Ayrıca ülkemizde sosyal görünüş kaygısını cinsiyet değişkeni açısından inceleyen çalışmalarda çelişkili sonuçlar ortaya çıkmıştır. Bu bakımdan Türkiye'de yapılan çalışmaların sonuçlarının meta-analiz yöntemi ile birleştirilip bir çerçeve ortaya konması literatürdeki boşluğu dolduracak ve çelişkili bulgulara son noktayı koyacaktır.

\section{Yöntem}

Bu araştırmada meta analiz yöntemi kullanılmıştır. Meta-analiz, belirli bir konuda yapılmış, birbirinden bağımsız, birden çok çalışmanın sonuçlarını birleştirme ve elde edilen araştırma bulgularının istatistiksel analizini yapma yöntemidir (Akgöz, Ercan, ve Kan, 2004). Meta-analiz yönteminin temel bulguları etki büyüklüğü, heterojenlik testi sonuçları ve yayım yanlılığı bulgularından oluşmaktadır. Araştırmanın etki büyüklükleri Comprehensive Meta-Analysis (CMA) yazılımı kullanılarak yapılmıştır. Sabit ve rastgele etkiler modeline göre etki büyüklükleri hesaplanmış, elde edilen etkiler sosyal bilimler alan çalışmalarına uygun olarak rastgele 
etkiler modeline göre değerlendirilmiştir (Cumming, 2012). Etki büyüklüklerinin heterojenliği Q ve $\mathrm{I}^{2}$ istatistiği ile değerlendirilmiş ve heterojen bir dağılım gösterdiği belirlenmiştir.

\section{Alan taramasi}

Araştırmanın veri kaynağını Türkiye'de sosyal görünüş kaygısı konulu lisansüstü tezler ve makaleler oluşturmaktadır. Taramada Türkçe olarak "Sosyal Görünüş Kaygısı", ve İngilizce olarak ise "Social Appearance Anxiety" kelimeleri anahtar sözcük olarak kullanılmıştır. 2013'den 2018'e kadar 129 çalışma tarama sonucu belirlenmiştir. Ancak dâhil edilme kriterlerine uyan 29 çalışma bu meta-analize dâhil edilmiştir.

\section{Dâhil edilme kriteri}

Meta-analize dâhil edilebilmek için çalışmalarda aranan kriterler:

1. Lisansüstü tezlere YÖK tez veri tabanında tam metin olarak ulaşılabilmesi.

2. Makalelerin hakemli bilimsel dergilerde yayınlanmış olması.

3. Çalışmaların etki büyüklügünün hesaplanabilmesini sağlayacak sayısal verileri içermesi.

4. Çalışmaların dilinin Türkçe ya da İngilizce olması.

5. Çalışmaların Türkiye örnekleminde gerçekleştirilmiş olması.

6. Meta-analiz çalışmasında bu kriterleri karşılayan 29 çalışmanın etki büyüklüğü hesaplanmıştır.

\section{Çalışmaların kodlanması ve kodlama sürecinin güvenirliği}

Yapılan meta-analiz çalışmasında etki büyüklügü çeşidi olarak Standardize Ortalamalar Fark1 (SOF) kullanılmıştır. Araştırmanın etki büyüklüğünü hesaplamak için her çalışmadan örneklem büyüklüğü (kadın/erkek) ve veriler (ortalama ve standart sapma, $\mathrm{t}, \mathrm{p}$ değerleri) elde edilmiştir. Yapılan çalışmada kadın=1 erkek=0 şeklinde kodlanmıştır. Araştırmada pozitif ekti büyüklüğü kadınların, negatif etki büyüklüğü erkeklerin daha fazla sosyal görünüş kaygısı yaşadığı anlamına gelmekte- 
dir. Meta-analize dâhil edilen çalışmaların ergen ya da yetişkin örnekleminde gerçekleştirilmiş olması araştırmada moderatör değişken olarak belirlenmiştir.

Araştırmanın kodlayıcılar arasındaki güvenirliğini sağlamak amacıyla iki bağımsız kodlayıcı tarafından kodlanması sağlanmışır ve kodlayıcı arasındaki uyumun değerlendirilmesi amacıyla Cohen Kappa katsayısı kullanılmıştır. Yapılan çalışmada Cohen Kappa katsayısı $\kappa=0,92$ (mükemmel uyum) olarak bulunmuştur.

\section{Araştırmaya dâhil edilen çalışmaların genel özellikleri}

Araştırmaya dâhil edilen 29 çalışma 2013-2018 yılları arasında yapılmıştır. Araştırmaya dâhil edilen çalışmalar cinsiyet açısından incelendiğinde 7340'si kadın ve 6425'si erkek, toplam 13765 kişiden oluşmaktadır. Çalışmaların 10'u tez, 14'ü makale, 5'i tezden üretilmiş makaleden oluşmaktadır. Çalışmaların 8'i ergen 21'i yetişkin örnekleminden oluşmaktadır. Araştırmaya dâhil edilen çalışmaların tamamında Doğan (2010) tarafından geliştirilmiş Sosyal Görünüş Kaygısı Ölçeği ve Doğan (2011) tarafında geliştirilmiş Sosyal Görünüş Kaygısı Ölçeği Ergen Formu kullanılmıştır.

\section{Bulgular}

$\mathrm{Bu}$ bölümde araştırmaya dâhil edilen çalışmaların ayrı ayrı etki büyüklükleri, çalışmalara ait birleştirilmiş etki büyüklükleri, homojenlik testi sonuçları, yayın yanlılı̆̆ ile ilgili bulgular ve moderatör değişkenlere göre analiz sonuçları verilmiştir.

\section{Yayın yanlılı̆̆}

Yayın yanlılığı, pozitif ve istatistiksel anlamlılık bulunan çalışmaların yayınlanması eğilimi olarak ifade edilebilir (Borenstein vd., 2009). Yapılan çalışmada yayım yanlılı̆̆ını test etmek için Huni grafiği, Orwin Güvenli N Sayısı, Egger testi ve Duval ve Tweedie'nin kırp doldur yöntemi kullanılmıştır. 
Huni grafiği meta-anlizde kullanılan veri setinin görsel bir özetini sunmaktadır (Sterne, Becker ve Egger, 2005). Çalışma yanlılığını belirlemek amacıyla yapılan ilk test olan Funnel Testi'nin grafiksel gösterimi şu şekildedir:

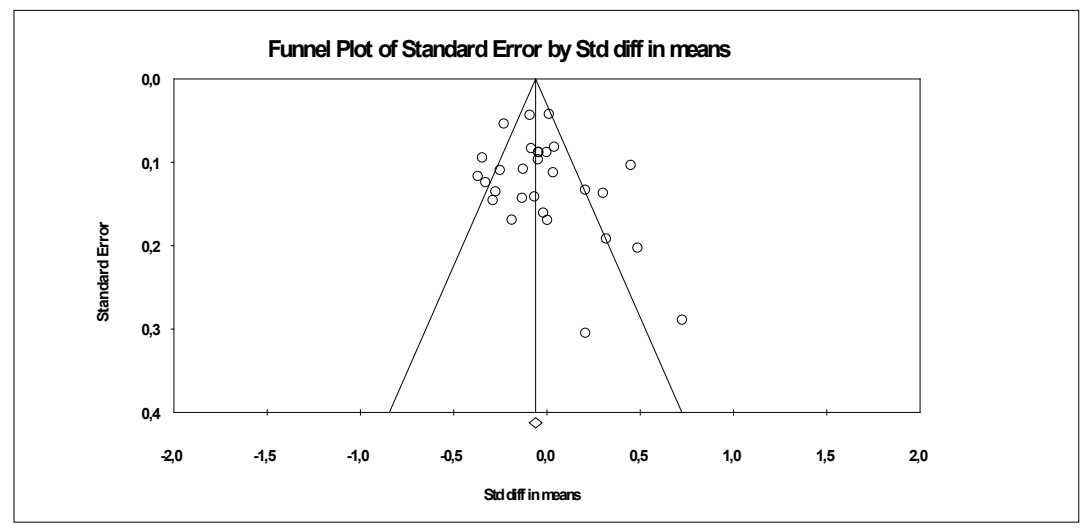

Şekil 1. Meta-analize dâhil edilen çalışmaların yayım yanlılı̆̆ına ilişkin huni grafiği

Şekil 1'de görüldüğü gibi, araştırmaya dâhil edilen 29 çalışma etki büyüklüğü dikey çizgisinin her iki yanına eşit bir şekilde dağıldığı görülmektedir. Veri setini oluşturan 29 çalışmanın eşit bir şekilde genellikle üst bölgede dağılıyor olması yayın yanlılığının olmadığını göstermektedir.

Tablo 1. Meta-analize dahil edilen çalişmalarn yanlılık durumunu gösteren test verileri

\begin{tabular}{llll}
\hline $\begin{array}{l}\text { Orwin's } \\
\mathrm{N}\end{array}$ & Fail-Safe & Egger Testi & \multicolumn{2}{l}{$\begin{array}{l}\text { Duval veTweedie'nin Kırp ve doldur } \\
\text { yöntemi }\end{array}$} \\
\cline { 3 - 4 } & & Kırpılan çalışma & $\begin{array}{l}\text { SOF Gözlenen } \\
\text { (doldurulan) }\end{array}$ \\
\hline$-0,01$ SOF için 148 & $p=0,28$ (çift kuyruk) & 2 & $-0,040(-0,060)$ \\
\hline
\end{tabular}

Yayın yanlılığının test etmek için yapılan Orwin's Fail-Safe N hesaplamasına göre yapılan çalışmanın etki büyüklügünü $-0,01$ düzeyine getirebilecek yayımlanmamış çalışma sayısı 148 olarak hesaplanmıştır. Bu rakam meta-analiz bulgularının anlamsız hale getirmek için veri setine alınan çalışmaların beş katı çalışmaya daha ihtiyaç olduğu anlamına gelmektedir. Analize dâhil edilen çalışmalar Türkiye'de sosyal görünüş 
kaygısı üzerine yapılmış ve dâhil edilme kriterine göre ulaşılabilmiş çalışmaların tamamıdır. Bu bağlamda analiz sonucunu farksız düzeye indirecek 148 çalışmaya ihtiyaç duyulması bu meta-analizde yayın yanlılığının olmadığının bir diğer göstergesi olarak kabul edilebilir.

Yayın yanlılığının test etmek için Egger'in regresyon testi yapılmış olup $\mathrm{p}=0.28(\mathrm{p}>.05)$ yayın yanlılığının olmadığını göstermektedir. Ayrıca Duval ve Tweedie'nin kırp ve doldur yöntemi sonucuna göre, 2 emsal çalışma dâhil edildiğinde, -0.040 ortalama etki büyüklüğünün, -0.060 olarak değiştiği görülmektedir. Bu değişiklik, önemsiz düzeyde olduğu için elde edilen etki büyüklügünün güvenilir olduğu kabul edilebilir.

\section{Cinsiyete göre etki büyüklükleri analizinin birleştirilmemiş bulguları}

Sosyal görünüş kaygısı değişkeninin cinsiyete göre etki büyüklükleri, standart hata ve \% 95'lik güvenirlik aralığına göre alt ve üst sınırları Tablo 2'de verilmiştir.

Tablo 2. Sosyal görünüş kaygısına ilişkin cinsiyet etki büyüklükleri

\begin{tabular}{llllll}
\hline & Cohen & Alt sinır & Üst s1- & Z de- & p \\
Çalışma (Yazar, Yıl) & $\mathrm{d}$ & & nır & ğeri & \\
\hline Ağırnaslıgil, Amuk, 2018 & 0,21 & $-0,39$ & 0,81 & 0,68 & 0,50 \\
Alemdağ, Öncü, 2015 & $-0,09$ & $-0,18$ & $-0,01$ & $-2,07$ & 0,04 \\
Altun Dinç, 2016 & $-0,04$ & $-0,22$ & 0,13 & $-0,49$ & 0,62 \\
Amil, Bozgeyikli, 2015 & $-0,05$ & $-0,24$ & 0,14 & $-0,48$ & 0,64 \\
Atik, Atik, Asaf Çınar, 2015 & 0,73 & 0,16 & 1,29 & 2,51 & 0,01 \\
Ben, 2017 & $-0,02$ & $-0,33$ & 0,30 & $-0,11$ & 0,91 \\
Çakmak, 2018 & 0,00 & $-0,33$ & 0,34 & 0,02 & 0,98 \\
Ciba, 2018 & $-0,37$ & $-0,60$ & $-0,14$ & $-3,15$ & 0,00 \\
Çelik, Turan, 2014 & $-0,33$ & $-0,57$ & $-0,08$ & $-2,63$ & 0,01 \\
Dönmez, 2018 & 0,49 & 0,09 & 0,89 & 2,40 & 0,02 \\
Erdemir, Bagcı, İnan, Turan, 2013 & 0,32 & $-0,06$ & 0,70 & 1,66 & 0,10 \\
Erman, 2017 & 0,45 & 0,25 & 0,65 & 4,35 & 0,00 \\
Göksel, Caz, Yazıcı, Zorba, 2018 & 0,21 & $-0,05$ & 0,47 & 1,55 & 0,12 \\
Gül, 2016 & 0,04 & $-0,19$ & 0,26 & 0,31 & 0,76 \\
Işıkol Özge, 2013 & 0,00 & $-0,17$ & 0,17 & 0,00 & 1,00 \\
İsmail, 2018 & $-0,07$ & $-0,34$ & 0,21 & $-0,47$ & 0,64 \\
Kalemoğlu Varol, Erbaş, Ünlü, 2014 & $-0,13$ & $-0,34$ & 0,09 & $-1,17$ & 0,24 \\
Karaca Doğan, 2018 & 0,30 & 0,03 & 0,57 & 2,21 & 0,03 \\
Kılıç, Karakuş, 2015 & $-0,23$ & $-0,34$ & $-0,12$ & $-4,23$ & 0,00 \\
Korkmaz, 2017 & $-0,13$ & $-0,41$ & 0,15 & $-0,92$ & 0,36 \\
Şahin, Barut, Ersanlı, Kumcağ1Z, 2014 & 0,02 & $-0,06$ & 0,11 & 0,51 & 0,61 \\
Seki, Dilmaç, 2015 & 0,04 & $-0,12$ & 0,20 & 0,50 & 0,62 \\
\hline
\end{tabular}




\begin{tabular}{llllll}
\hline Senger, 2017 & $-0,35$ & $-0,53$ & $-0,16$ & $-3,64$ & 0,00 \\
Soylu, Atik, Öçalan, 2017 & $-0,25$ & $-0,47$ & $-0,04$ & $-2,28$ & 0,02 \\
Tekeli, 2017 & $-0,29$ & $-0,57$ & 0,00 & $-1,98$ & 0,05 \\
Türker, Er, Eroğlu, Şentürk, Durmaz, & $-0,04$ & $-0,22$ & 0,13 & $-0,50$ & 0,62 \\
2018 & & & & & \\
Var, Karabulut, Atasoy, 2018 & $-0,27$ & $-0,54$ & $-0,01$ & $-2,02$ & 0,04 \\
Vural, Keskin, Çoruh, 2017 & $-0,19$ & $-0,52$ & 0,15 & $-1,10$ & 0,27 \\
Yüceant, Ünlü, 2017 & $-0,08$ & $-0,25$ & 0,08 & $-0,99$ & 0,32 \\
\hline
\end{tabular}

Tablo 2'ye göre, araştırmaya dâhil edilen 29 çalışmanın cinsiyete göre standardize edilmiş etki büyüklükleri -0.37 erkekler lehine değer ile 0.73 kadınlar lehine değer arasında değişmektedir. Meta-analize dâhil edilen 12 çalışmada istatistiksel anlamlı farklılık bulunurken, 17 çalışmada anlamlı bir farklılık bulunmamıştır. Veri setinde yer alan 29 çalışmanın güven aralığı -0.60 ile 1,29 arasında değişmektedir.

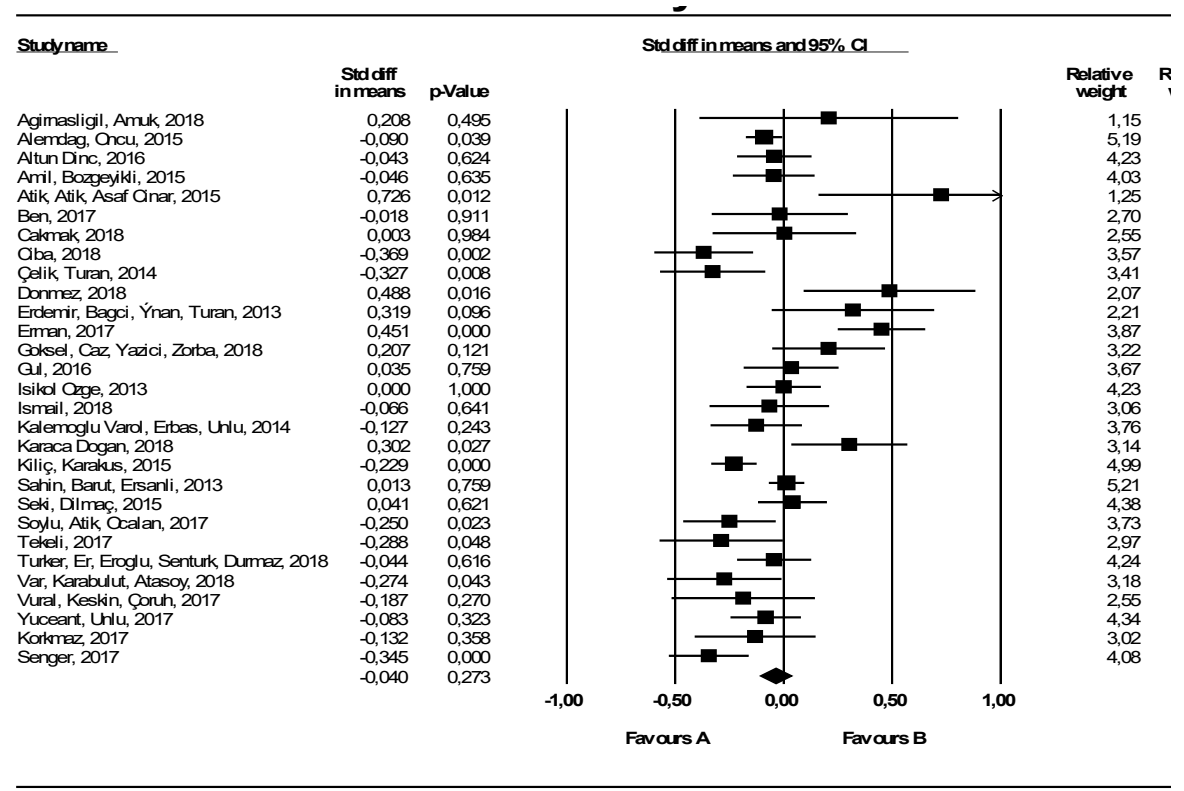

Şekil 2. Sosyal görünüş kaygısı değgişkeninin cinsiyete göre incelenmesine ilişkin orman grafiği

Şekil 2' de, sosyal görünüş kaygısı değişkeninin cinsiyete göre incelenmesine ilişkin orman grafiği verilmiştir. Bu şekil cinsiyet değişkenin sosyal görünüş kaygısı üzerindeki etkisini inceleyen 29 çalışmadan elde 
edilen Cohen's $d$ verilerini içermektedir. Bu grafikte, kareler her bir çalışmanın etki büyüklüğünü, iki yanından uzanan çizgiler de tahmin için \%95 güven aralığını göstermektedir. En sonda yer alan elmas genel etki büyüklüğü tahmini ve ona ait güven aralığını temsil edilmektedir (Üstün ve Eryılmaz, 2014).

\section{Cinsiyete ilişkin etki büyüklügü temel analiz bulguları}

$\mathrm{Bu}$ çalışmada sosyal görünüş kaygısı düzeylerinin cinsiyet değişkenine göre farklılığın olup olmadığı incelenmektedir. Yapılan araştırmaya ait homojenlik testi, sabit etki modeli ve rastgele etkiler modeline göre yapılan analizlerin sonuçları Tablo 3'te verilmiştir.

Tablo 2. Etki modeline göre ortalama etki büyüklükleri ve güven aralığı alt ve üst değerleri

\begin{tabular}{|c|c|c|c|c|c|c|c|}
\hline \multirow{2}{*}{ Model } & \multirow{2}{*}{$\mathrm{N}$} & \multirow{2}{*}{$\begin{array}{l}\text { Cohen's } \\
d\end{array}$} & \multicolumn{2}{|c|}{$\begin{array}{l}\text { \%95 Güven Ara- } \\
\text { lığ1 }\end{array}$} & \multicolumn{3}{|c|}{ Heterojenlik } \\
\hline & & & $\begin{array}{l}\text { Alt S1- } \\
\text { nir }\end{array}$ & $\begin{array}{l}\text { Üst S1- } \\
\text { nir }\end{array}$ & $\begin{array}{l}\text { Q-de- } \\
\text { ğeri }\end{array}$ & $\mathrm{P}$ & $\mathrm{I}^{2}$ \\
\hline $\begin{array}{l}\text { Sabit etkiler } \\
\text { modeli }\end{array}$ & 29 & $-0,061$ & $-0,095$ & $-0,027$ & 100,628 & 0,000 & 72,175 \\
\hline $\begin{array}{l}\text { Rastgele etkiler } \\
\text { modeli }\end{array}$ & 29 & $-0,040$ & $-0,112$ & 0,032 & & & \\
\hline
\end{tabular}

Tabloya bakıldığında I2 değerinin \%72,175 (\% 25 düşük düzeyde heterojenliği, \% 50 orta düzeyde heterojenliği ve \% 75 yüksek) olduğu görülmektedir. Araştırma verilerinin heterojenlik sonuçlarına göre $(\mathrm{Q}=100,628 ; \mathrm{p}<.01)$ dağılımın heterojen olduğu söylenebilir (Higgins ve Thompson, 2002). Rastgele etkiler modeline göre \%95 güven aralığının alt sinırı -0,112, üst sinırı 0,032 ve etki büyüklüklerinin ortalaması $-0,040$ olarak hesaplanmıştır. Elde edilen bulgular, cinsiyetin sosyal görünüş kaygısı üzerinde düşük düzeyde etkili olduğu şeklinde yorumlanabilir (Cohen, 1988). Araştırma bulgularına göre sosyal görünüş kaygısı erkeklerde kadınlardan daha yüksek çıkmıştır ancak elde edilen değer önemsiz düzeydedir. Ayrıca elde edilen sonucun $\mathrm{p}=0.27$ ile istatistiksel anlamlılı̆ga sahip olmadığı bulunmuştur. 


\section{Moderatör analizi}

Yapılan araştırmada sosyal görünüş kaygısını cinsiyet açısından meta-analize dâhil edilen çalışmalar örneklem grubuna göre incelenmiş, elde edilen bulgular Tablo 3'te verilmiştir.

Tablo 3. Çalışmanın yapıldı̆̆ı örneklem grubuna göre moderatör analizi

\begin{tabular}{|c|c|c|c|c|c|c|c|}
\hline \multirow{2}{*}{ Model } & \multirow{2}{*}{$\mathrm{N}$} & \multirow{2}{*}{$\begin{array}{l}\text { Cohen's } \\
d\end{array}$} & \multicolumn{2}{|c|}{$\begin{array}{l}\text { \%95 Güven Ara- } \\
\text { lığ1 }\end{array}$} & \multirow[b]{2}{*}{$\mathrm{P}$} & \multirow[b]{2}{*}{$\mathrm{Qb}^{\mathrm{b}}$} & \multirow[b]{2}{*}{$\mathrm{P}$} \\
\hline & & & $\begin{array}{l}\text { Alt S1- } \\
\text { nir }\end{array}$ & $\begin{array}{l}\text { Üst S1- } \\
\text { nir }\end{array}$ & & & \\
\hline Ergen & 8 & $-0,058$ & $-0,140$ & 0,025 & 0,169 & 0,382 & 0,536 \\
\hline Yetişkin & 21 & $-0,017$ & $-0,118$ & 0,085 & 0,749 & & \\
\hline
\end{tabular}

Tablo 3'te görüldüğü gibi, çalışmanın yapıldığ 1 örneklem grubuna göre cinsiyete göre etki büyüklüğü değeri ergenler için -0,058, yetişkinler için 0.017 olarak hesaplanmıştır. Örneklem grubu moderatörü için çalışmalar arası varyans istatistiksel olarak anlamlı değildir $\left(Q_{b}=0,382, p>0,05\right)$. Çalışmanın örneklem grubunun cinsiyete göre etki büyüklüğünü anlamlı derecede değiştirmediği bulunmuştur.

\section{Sonuç ve tartışma}

$\mathrm{Bu}$ araştırma kapsamında, Türkiye örnekleminde sosyal görünüş kaygısının cinsiyet (kadın/erkek) açısından anlamlı bir farklılaşma gösterip göstermediğini ortaya koymak ve ortaya çıkabilecek farklılığın ergen ve yetişkinler açısından moderatör etkisini belirlemek amacıyla meta-analiz çalışması yürütülüştür. Yapılan taramalarda, Türkiye'de 2013-2018 yıllarında konu ile ilgili yapılan 129 çalışma belirlenmiştir. Bu çalışmaların araştırmaya dâhil edilmesinde birtakım kriterler koyulmuş ve bu kriterler doğrultusunda $10^{\prime}$ u tez, 14'ü makale, 5'i tezden üretilmiş makaleden oluşan 29 çalışma araştırmaya dâhil edilmiştir. Bu çalışmaların araştırmaya dâhil edilmesinde yayın yanlılığı olup olmadığını belirlemek için Orwin's Fail-Safe N hesaplaması, huni saçılım grafiği, Egger'in regresyon testi, Duval ve Tweedie'nin Kırp ve Doldur yöntemi kullanılmış ve sonuçlar yayın yanlılığının olmadığını göstermiştir. Ayrıca verilerin 
heterojenlik sonuçları dağılımın heterojen olduğunu göstermiştir $(\mathrm{Q}=100,628 ; \mathrm{p}<.01)$. Yapılan çalışmada sosyal bilimler alanına uygun olarak rastgele etkiler modeli tercih edilmiştir. Rastgele etkiler modelinde erkekler lehine $-0,040$ 'lük [-0.112, 0.032] ancak istatistiksel olarak anlamlı olmayan bir etki büyüklüğü hesaplanmıştır. Sosyal görünüş kaygısı düzeyinin ergen ve yetişkinler açısından cinsiyete göre farklılaşıp farklılaşmadığını incelemek için moderatör değişkenler analizi yapılmıştır. Analiz sonucunda, etki büyüklüğü değeri ergenler için -0,058, yetişkinleri için -0.017 olarak hesaplanmıştır. Yani çalışmanın örneklem grubunun (ergen-yetişkin) cinsiyete göre etki büyüklügünün anlamlı düzeyde değişmediği bulunmuştur $\left(\mathrm{Q}_{b}=0,382, \mathrm{p}>0,05\right)$.

Tarih boyunca vücut imajından memnuniyetsizlik çoğu zaman kadınları etkileyen bir konu olarak ele alınmıştır. Fakat son zamanlarda yapılan çalışmalar erkeklerin de artan bir şekilde vücut imajlarından memnuniyetsizlik duyduğunu göstermektedir (Brennan, Lalonde, ve Bain, 2010). Örneğin Feingold ve Mazzella'nın (1998) 222 araştırma sonucunu birleştirerek çekicilik ve beden imajının cinsiyete göre anlamlı düzeyde farklılaşıp farklılaşmadığını ortaya koymak amacıyla yürüttüğü meta-analiz çalışması, erkeklerin kadınlara göre vücutlarından tatmin olma derecesinin yüksek olsa da aradaki farkın düşük düzeyde olduğunu göstermiştir. Ayrıca kendini fiziksel olarak çekici bulma açısından erkekler ve kadınlar arasında anlamlı bir farklılaşma bulunamamıştır. Araştırmacılar yetişkin ve ergen örnekleminde cinsiyet farklılaşmasını incelediklerinde, bu farklılığın yetişkinlerde ergenlere göre daha düşük olduğu sonucunu bulmuşlardır. Bir başka araştırmada Brennan ve arkadaşları (2010) kadınların vücut imajından tatminsizliği daha yüksek olsa da erkeklerin de yüksek oranda tatminsizlik yaşadığını tespit etmiştir.

Araştırma sonucunda elde ettiğimiz sonuç Hyde' in (2005) cinsiyet benzerlikleri hipotezini doğrulamaktadır. Hyde (2005) kadın ve erkekler tüm psikolojik değişkenler olmasa da çoğunda cinsiyetler arasında farklılaşma olmadığını ileri sürmektedir. Yaptığ 46 meta-analiz çalışması ile de bu hipotezini doğrulamıştır. Türkiye örnekleminde yapılan çalışmalara bakıldığında araştırma sonuçları ile paralellik gösteren çok sayıda çalışmanın olduğunu söylemek mümkündür (Altun Dinc, 2016; Ben, 2017; Ersanli, 2013; Göksel, Caz, Yazıcı, ve Zorba, 2018; Gül, 2016; Kalemoglu Varol, Erbas, Unlu, 2014; Sahin, Barut, ve Tekeli, 2017). Yine uluslararas1 
literatüre bakıldığında sosyal görünüş kaygısının cinsiyetler açısından farklılaşmadığına işaret eden araştırmalar mevcuttur (Dakanalis ve diğerleri, 2015; Ko, 2010).

Literatürde araştırma sonuçları ile benzerlik gösteren çalışmaların yanı sıra sosyal görünüş kaygısının erkeklerde (Alemdağ ve Öncü, 2015; Ciba, 2018; Çelik, Turan, 2014; Senger, 2017; Soylu, Atik, ve Ocalan, 2017; Var, Karabulut, ve Atasoy, 2018) ya da kadinlarda (Atik, Atik, Asaf, ve Cinar, 2015; Dönmez, 2018; Erdemir, Bagci, İnan, ve Turan, 2013) daha yüksek olduğuna işaret eden çalışmalar da bulunmaktadır.

Yapılan meta-analiz çalışması Türkiye örneklemi üzerinde yapılan çalışmaları sentezleyerek birleştirmesi açısından güçlü bir karakteristiğe sahip olsa da çalışmanın birtakım sınırlı yönleri bulunmaktadır. Örneğin, çalışmanın sadece nicel boyutta bir araştırma olması, elde edilen sonuçların yüzeysel kalmasına yol açmaktadır. Çalışmada moderatör değişkenin sadece ergen-yetişkin olarak alınması ve sadece Türk örnekleminin araştırmaya dâhil edilmesi bir sinırlılık olarak düşünülebilir. Bu sınırlılıklar göz önüne alındığında; konunun daha derinlemesine anlaşılabilmesi için nitel çalışmaların ve boylamsal araştırmaların yapılması yararlı olabilir. Uluslararası literatürde sosyal görünüş kaygısının cinsiyet açısından incelendiği bir çalışma bulunmadığı düşünüldüğünde, farklı kültürlerde benzer meta-analiz çalışmaları yapılması yararlı olabilir. Ayrıca kültürler arasında bir farklılık olup olmadığını tespit etmek amacıyla yeni çalışmalar yürütülebilir. 


\title{
EXTENDED ABSTRACT
}

\section{Gender Differences in Social Appearance Anxiety: A Meta-Analysis Study}

\author{
Zeynep Şimşir - Tolga Seki - Bülent Dilmaç \\ Necmettin Erbakan University
}

People are aware of their own physical characteristics and have a perception on it (Çınar \& Keskin, 2015; Gofmann, 1959) Leary \& Kowalski, 1990). Cultural and social elements, demographic characteristics, mass media and fashion have a significant impact in shaping this perception. These elements develop an ideal appearance image that is ideally influenced by the body structure and ideal structure (Çepikkurt \& Coşkun, 2010; Grogan, 2008; Kılıç, 2015; Smolak, 2002). The self-perception of a person does not match the image of the ideal body that is being imposed, leads to a refusal of self-acceptance and a negative perception of its appearance (K1lıç, 2015; Sabiston, Crocker, \& Munroe-Chandler, 2005).

The fact that the individual has a negative body image related to the physical appearance is called the social appearance anxiety (Doğan, 2010). Social appearance anxiety is a sub-dimension of social anxiety and defined as concerns involving other people's assessments of the physical appearance of the individual (Hart, Leary, \& Rejeski, 1989; Hart, Flora, Palyo, Fresco, Holle, \& Heimberg, 2008). Hart et al. (2008) stated that the social appearance anxiety includes not only physical features such as height and weight, but also individual skin color, eye color and facial structure. People who are not interested in how the body shape is evaluated by others experience a low level of social appearance; those who have negative irrational thoughts about their physical appearance and others who are sensitive to negative evaluations of their appearance have a chronic social appearance (Hart, Leary, \& Rejeski, 1989).

In our age, it has attracted the attention of the researchers that the body image imposed on women and men created a social appearance concern on a large number of people in the global context, especially adolescents, 
and a lot of research has been done on the subject both nationally and internationally. In the literature, there are many studies examining the social appearance anxiety on the Turkish sample in terms of demographic variables. However, different results have been obtained in the studies examining whether the social appearance anxiety differs according to gender. In this study, it is aimed to reveal a synthesis by combining the meta-analysis of the researches which examine whether the social appearance anxiety on the Turkish sample differs from the gender.

\section{Method}

Meta-analysis method was used in this study. The effect size of the study was done by using Comprehensive Meta-Analysis (CMA) software. The effect sizes were calculated according to the fixed and random effects model, and the obtained effects were evaluated according to the random effects model in accordance with the social sciences field studies (Cumming, 2012). The heterogeneity of the effect sizes was evaluated with the $\mathrm{Q}$ and $\mathrm{I}^{2}$ statistics and it was determined that they showed a heterogeneous distribution.

In this study, Cohen $d$ was used as the effect size coefficient. 129 studies conducted on the subject in the years 2013 to 2018 were identified in Turkey during the literature review process. 29 studies (10 theses, 13 articles and 5 theses articles) which were appropriate for inclusion criteria were concluded. The total sample of study was 13765 people, 6425 of whom were males and 7365 whom were females.

The criteria to be included in the meta-analysis are as follows:

1. To be able to reach graduate theses as a full text in YÖK thesis database.

2. Selected articles are published in peer-reviewed scientific journals.

3. Studies to include quantitative data to calculate the effect size.

4. The language of the studies is Turkish or English.

5. Studies has been carried out in Turkey of the sample.

6. In the meta-analysis study, the effect size of 29 studies that met these criteria was calculated. 


\section{Results}

Orwin's Fail-Safe N calculation, funnel scattering graph, Egger regression test, Duval and Tweedie Crop and Fill method were used to determine the publication bias. The results showed no publication bias. Furthermore, the heterogeneity of the data showed that the distribution was heterogeneous $(\mathrm{Q}=100,628 ; \mathrm{p}<.01)$. In the study, random effects model was preferred in accordance with the field of social sciences. In the random effects model, an effect size of $-0,040[-0.112,-0.032]$ but not statistically significant was calculated in favor of men. Moderator variables analysis was performed to determine whether the social appearance anxiety level varies according to gender in terms of adolescents and adults. As a result of the analysis, the effect size value was calculated as $-0,058$ for adolescents and -0.017 for adults. In other words, it was found that the effect size of the study group (adolescent-adult) did not change significantly by gender $\left(\mathrm{Q}_{b}=0,382\right.$, $\mathrm{p}>0,05)$. The conclusion of the study was discussed and suggestions are given in line with the literature.

\section{Kaynakça / References}

Yıldız işareti ile işaretlenmiş çalışmalar meta-analize dâhil edilen çalışmaları göstermektedir.

*Ağırnaslıgil, M. Ö., ve Amuk, N. G. (2017) İskeletsel sınıf III maloklüzyona sahip ortognatik cerrahi hastalarının cerrahi öncesi ve cerrahi sonrasında benlik saygisı, eleştiriye duyarlılık ve sosyal görünüş kaygısı düzeylerinin değerlendirilmesi. Selcuk Dental Journal, 5(1), 50-58.

*Alemdağ, S., ve Erman, Ö. (2015). Öğretmen adaylarının fiziksel aktiviteye katılım ve sosyal görünüş kaygılarının incelenmesi. International Journal of Science Culture and Sport, 3(3), 287-300.

*Altun Dinc, M. (2016). Lise öğrencilerinin sosyal görünüş kayg̨ları. (Yayımlanmamış yüksek lisans tezi). Ondokuz Mayıs Üniversitesi, Samsun. 
*Amil, O., ve Bozgeyikli, H. (2015). Investigating the relationship between social appearance anxiety and loneliness of Turkish University youth. Journal of Studies in Social Sciences, 11(1), 68-96.

*Atik, D., Atik, C., Asaf, R., ve Cinar, S. (2015). The effect of perceived social support by hemodialysis patients on their social appearance anxiety. Medicine Science, 4(2), 2210-2223.

Banfield, S. S., ve McCabe, M. (2002). An evaluation of the construct of body image. Adolescence, 37(146), 373-393.

*Ben, S. (2017). İstanbul'da yaşayan üniversite öğrencilerinin sosyal anksiyete düzeyleri ile beden algısı olumsuz değerlendirilme korkusu sosyal görünüş kaygısı arasındaki ilişkinin incelenmesi. (Yayımlanmamış yüksek lisans tezi). Haliç Üniversitesi, İstanbul.

Borenstein, M., Hedges, L., Higgins, J., ve Rothstein, H. (2005). Comprehensive meta analysis version 2. Englewood, NJ: Biostat.

Brennan, M. A., Lalonde, C. E., ve Bain, J. L. (2010). Body image perceptions: Do gender differences exist. Psi Chi Journal of Undergraduate Research, 15(3), 130-138.

Cash, T. F. (2004). Body image: Past, present, and future. Body Image, 1(1), 1-5. doi:10.1016/S1740-1445(03)00011-1

*Ciba, B. (2018). üniversite öğrencileri arasında sosyal medya kullanımı ve sosyal kayğ arasındaki ilişkinin incelenmesi. (Yayımlanmamış yüksek lisans tezi). Yakın Doğu Üniversitesi, Lefkoşa.

Cohen, J. (1988). Statistical power analysis for the behavioral sciences. US: Lawrence, Erlbaum.

*Çakmak, M. (2018). Üniversite öğrencilerinin sosyal medya kullanım düzeyleri ile sosyal görünüş kaygısı arasındaki ilişkinin farklı değiş̧kenler açısından değerlendirilmesi. (Yayımlanmamış yüksek lisans tezi). Beykent Üniversitesi, İstanbul.

${ }^{*}$ Çelik, E., Turan, M. E., ve Arıcı, N. (2014). The role of social appearance anxiety in meta-cognitive awareness of adolescents. International Journal of Learning, Teaching and Educational Research, 7(1), 138-147.

Çepikkurt, F., ve Çoşkun, F. (2010). Üniversiteli dansçıların sosyal fizik kaygı ve beden imgesinden hoşnut olma düzeyleri. Pamukkale Spor Bilimleri Dergisi, 1(2), 17-24. 
Doğan, T. (2010). Sosyal görünüş kaygisı ölçeği'nin (SGKÖ) Türkçe uyarlaması: Geçerlik ve güvenirlik çalışması. Hacettepe Üniversitesi Ĕ̆itim Fakültesi Dergisi, 39(39), 151-159.

Doğan, T., Sapmaz, F., ve Totan, T. (2011). Beden imgesi baş etme stratejileri ölçeğinin türkçe uyarlaması: Geçerlilik ve güvenilirlik çalışması. Anatolian Journal of Psychiatry/Anadolu Psikiyatri Dergisi, 12(2), 121-129.

*Dönmez, Ş. N. (2018). Evli çiftlerde sosyal görünüş kaygısı ile cinsel doyum arasındaki ilişkinin incelenmesi. (Yayımlanmamış yüksek lisans tezi). Üsküdar Üniversitesi, İstanbul.

*Erdemir, A. V., Bağcı, S. I., Yüksel İnan, E., ve Turan, E. (2013). Akne vulgarisli hastalarda sosyal görünüş kaygısı ve yaşam kalitesinin değerlendirilmesi. İstanbul Med, 1, 35-9. Doi: 10.5152/imj.2013.08

*Erman, M. S. (2017). Spor yapan ve yapmayan üniversite öğrencilerinin benlik saygı ve sosyal görünüş kaygı düzeylerinin incelenmesi. (Yayımlanmamış yüksek lisans tezi). Düzce Üniversitesi, Düzce.

Feingold, A., ve Mazzella, R. (1998). Gender differences in body image are increasing. Psychological Science, 9(3), 190-195.

Goffman, E. (2005). Introduction to the presentation of self in everyday life. In Hier, S. P. (Ed.), Contemporary sociological thought themes and theories (pp. 101-110). Toronto: Canadian Scholars' Press Inc.

${ }^{*}$ Göksel, A. G., Caz, Ç., Yazıcı, Ö. F., ve Zorba, E. (2018). Spor hizmeti alan bireylerin sosyal görünüş kaygısı ve öznel mutluluklarının incelenmesi. Gaziantep Üniversitesi Spor Bilimleri Dergisi, 3(3), 88101.

Grogan, S. (2008). Body image: Understanding body dissatisfaction in men, women, and children. Taylor\&Francis

*Gül, E. (2016). Ergenlerde sosyal görünüş kaygısı ve sosyal karşılaştırmanın fonksiyonel olmayan tutum ve bilişsel çarpıtmalarla ilişkisi. (Yayımlanmamış yüksek lisans tezi). Üsküdar Üniversitesi, İstanbul.

Hart, T. A., Flora, D. B., Palyo, S. A., Fresco, D. M., Holle, C., ve Heimberg, R. G. (2008). Development and examination of the social appearance anxiety scale. Assessment, 15(1), 48-59. 
Heilman, M. E., ve Stopeck, M. H. (1985). Being attractive, advantage or disadvantage? Performance-based evaluations and recommended personnel actions as a function of appearance, sex, and job type. Organizational Behavior and Human Decision Processes, 35(2), 202215.

Higgins, J. P. T. ve Thompson, S. G. (2002). Quantifying heterogeneity in a meta analysis. Statistics in Medicine, 21, 1539-1558.

Hyde, J. S. (2005). The gender similarities hypothesis. American psychologist, 60(6), 581-592.

*Işıkol Özge, F. (2013). İlköğretim II. kademe öğrencilerinin sosyal görünüş kaygıları ile benlik saygıları arasındaki ilişkinin incelenmesi. (Yayımlanmamış yüksek lisans tezi). Yeditepe Üniversitesi Üniversitesi, İstanbul.

*İsmail, M. (2018). Mutluluğun yordayıcısı olarak cinsel benlik şeması ve sosyal görünüş kaygısı. (Yayımlanmamış yüksek lisans tezi). İstanbul Ticaret Üniversitesi, İstanbul.

${ }^{*}$ Kalemoğlu, Y., Erbaş, M. K., ve Ünlü, H. (2014). Ergenlerin sosyal görünüş kaygıları ile beden eğitimi dersine yönelik tutumları arasındaki ilişki. Niğde Üniversitesi Beden Ĕ̆itimi ve Spor Bilimleri Dergisi, 8(1), 121-130.

*Karacan Doğan, P. (2018). Examining the relation between the fear of negative evaluation and the anxiety for social appearance in folk dancers. Journal of Education and Training Studies, 6(3), 59-65.

Kılıç, M. (2015). Üniversite öğrencilerinin sosyal görünüş kaygılarn ile benlik saygları ve yalnızlı düzeyleri arasındaki ilişkinin incelenmesi. (Yayımlanmamış yüksek lisans tezi). Selçuk Üniversitesi, Konya.

*Kılıç, M., ve Karakuş, Ö. (2016). Üniversite öğrencilerinin sosyal görünüş kaygıları ile benlik saygıları ve yalnızlık düzeyleri arasındaki ilişkinin incelenmesi. Journal of Human Sciences, 13(3), 3837-3852. doi:10.14687/jhs.v13i3.4054

Ko, N. (2010). The role of body shame, social appearance anxiety, and body checking behavior on body dissatisfaction and disordered eating behaviors: a crosscultural study in Germany and Korea (Doctoral dissertation, Universitätsbibliothek Freiburg). Retrieved from http://www.freidok.unifreiburg.de/volltexte/7926/. 
*Korkmaz, H. (2017). 16-24 yaş arası öğrencilerin yoğun ve bağımlı internet kullanımı ile sosyal görünüş kaygıları arasındaki ilişki. (Yayımlanmamış yüksek lisans tezi). Üsküdar Üniversitesi, İstanbul.

Leary, M. R., ve Kowalski, R. M. (1995). Social anxiety. New York: Guilford. Moe, B. (1999). Understanding the causes of a negative body image. Newyork: The Rozen Publishing Group.

Levinson, C. A., ve Rodebaugh, T. L. (2012). Social anxiety and eating disorder comorbidity: The role of negative social evaluation fears. Eating Behaviors, 13(1), 27-35.

Levinson, C. A., Rodebaugh, T. L., White, E. K., Menatti, A. R., Weeks, J. W., Iacovino, J. M., ve Warren, C. S. (2013). Social appearance anxiety, perfectionism, and fear of negative evaluation. Distinct or shared risk factors for social anxiety and eating disorders?. Appetite, 67, 125-133.

Mastro, S., Zimmer-Gembeck, M. J., Webb, H. J., Farrell, L., ve Waters, A. (2016). Young adolescents' appearance anxiety and body dysmorphic symptoms: Social problems, self-perceptions and comorbidities. Journal of Obsessive-Compulsive and Related Disorders, 8, 5055.

Özcan, H., Subaşı, B., Budak, B., Çelik, M., Gürel, Ş. C., ve Yıldız, M. (2013). Ergenlik ve genç yetişkinlik dönemindeki kadınlarda benlik saygısı, sosyal görünüş kayg1sı, depresyon ve anksiyete ilişkisi. Journal of Mood Disorders, 3(3), 107-13.

Sabiston, C. M., Crocker, P. R., ve Munroe-Chandler, K. J. (2005). Examining current-1deal discrepancy scores and exercise motivations as predictors of social physique anxiety in exercising females. Journal of Sport Behavior, 28(1), 68-86.

*Seki, T., ve Dilmaç, B. (2015). Predictor relationships between the values the adolescents have and their levels of subjective well-being and social appearance anxiety: A model proposal. Ĕğitim ve Bilim, 40(179), 57-67.

Smolak, L. (2002). Body image development in children. In T. H. Cash, ve T. Pruzinsky (Eds.), Body image a handbook of theory, research, and clinical practice. (pp. 65-73) içinde. NY: The Guilford Press 
*Soylu, Y., Atik, F., ve Öçalan, M. (2017). Ergenlerin sosyal görünüş kaygisı düzeylerinin incelenmesi (Kırıkkale ili örneği). Sportif Bakış: Spor ve Eğitim Bilimleri Dergisi, 1, 38-45.

Sterne, J. A. C., Becker, B. J., ve Egger, M. (2005). The funnel plot. H. R. Rothstein, A. J. Sutton, ve M. Borenstein (Ed.), Publication Bias in Meta-Analysis: Prevention, Assessment and Adjustments içinde (s. 7598). Chichester, UK: Wiley.

*Şahin, E., Barut, Y., ve Ersanli, E. (2013). Sociodemographic variables in relation to social appearance anxiety in adolescents. Online Submission, 15(1), 56-63.

Şahin, E., Barut, Y., Ersanli, E., ve Kumcagiz, H. (2014). Self-esteem and social appearance anxiety: An investigation of secondary school students. Online Submission, 4(3), 152-159.

*Tekeli, Ş. C. (2017). Beden eğitimi ve spor öğretmeni adaylar ile diğer öğretmen adaylarının sosyal görünüş kaygısı ve akademik öz-yeterlik düzeylerinin karşılaştırılması. (Yayınlanmamış yüksek lisans tezi). Bartın Üniversitesi, Bartın.

*Türker, A., Er, Y., Eroğlu, S. Y., Şentürk, A., ve Durmaz, M. (2018). Spor yapan bireylerin sosyal görünüş kaygısı ve benlik saygısının incelenmesi. Muş Alparslan Üniversitesi Uluslararası Spor Bilimleri Dergisi, 2(1), 8-15.

*Vural, M., Keskin, N., ve Çoruh, Y. (2017). Research of social appearance anxiety and self-efficacy of the students entered university by special talent exam. international Journal of Environmental and Science Education, 12( 9), 2063-2071.

Üstün, U., ve Eryılmaz, A. (2014). Etkili araştırma sentezleri yapabilmek için bir araştırma yöntemi: Meta-analiz. Eğitim ve Bilim, 39(174), 132.

*Yuceant, M., ve Unlu, H. (2017). The analysis of social appearance anxiety levels of physical education teacher candidates in terms of different variables. Turkish Journal of Sport and Exercise, 19(1), 102-108. 


\section{Kaynakça Bilgisi / Citation Information}

Şimşir, Z., Seki, T. ve Dilmaç, B. (2019). Sosyal görünüş kaygısında cinsiyet farklılıkları: Bir meta analiz çalışması. OPUS-Uluslararası Toplum Araştırmaları Dergisi , 10(17), 615-637. DOI: 10.26466/opus.519967 